\title{
Public Provision of Heroin for Addicts
}

\section{Harry Clarke}

7 he growth in heroin-induced overdose deaths in Australia, and other countries, has again raised the question of whether heroin should be supplied legally by governments to addicts. Australian overdose deaths from illegal drugs rose from 347 in 1988 to 600 in 1997 (National Drug and Alcohol Research Centre, 1999). These deaths are dominated, as a national health concern, by legal addictive substance deaths. In 1992, 19,920 deaths occurred due to active cigarette consumption and 3,660 to alcohol consumption (Australian Institute of Health and Welfare, 1996). The Prime Minister, Mr. Howard, has recorded his opposition even to a trial of public heroin provision.

Many critics in the media and academia have attacked his position. The issue itself is complex to analyse and many are adopting strong positions without providing a convincing rationale for their stance. Much of the discussion is highly emotional and based on the recent tragic deaths of young Australian addicts. Those rejecting public provision are often portrayed in the media as unfeeling (and unrealistic) while supporters are presented as socially-aware realists seeking to limit current deaths. However, if public provision leads to additional future addiction, then the pro-provision lobby's arguments might worsen, not improve the current serious situation. There are arguments suggesting that, under plausible circumstances, this unfortunate outcome will be a consequence of public provision.

The present paper evaluates the case for public provision. The policy framework adopted utilises both scientific knowledge and recent economic theories of addiction to assess arguments for public provision. Policy objectives are taken as given but are specified generally enough to capture a range of ethical positions adopted by participants in addiction policy debates. We propose two, possibly competing, social objectives:

- First, to minimise addiction itself. This is the abstinence objective. Addiction to (legal or illegally-supplied) heroin is regarded as intrinsically undesirable.

- Second, to minimise overdose deaths, other health hazards and crime costs associated with addicts stealing to finance their addiction. This is a harmminimisation objective. Given that addiction does occur, its social costs should be minimised.

Harry Clarke is Reader in Economics at La Trobe University. 
The basis for abstinence objectives is not straightforward to elicit since health and other risks associated with heroin use have not been clearly spelt out. Some long-term addicts have reasonable health and it is not clear that heroin damages vital organs. A possible argument against addiction is that heroin dependence is intrinsically undesirable. However, it can also be argued that the main health and legal problems associated with dependence are a consequence of criminalising drug use rather than dependence itself. The argument is that, because heroin is illegal, people commit crimes to obtain expensive supplies and may suffer health problems where supplies are of poor quality. Furthermore, to libertarians it is not obvious that the purely private pleasures yielded by narcotics should be penalised by law. Such sanctions penalise a state of being, not the costs heroin use imposes on society through crime and poor health. Such costs can, in principle, be managed efficiently by pricing health services correctly or by utilising full-liability sanctions on crimes.

It might be that some social groups choose to have social freedoms restricted to avoid the possibility of bad situations developing or because it is believed that some poorly-informed individuals (the 'young' for example) may make bad choices with serious, irreversible, long-term consequences. This raises questions as to who should constitute the relevant decision-making group. However, having raised the controversial question as to whether addiction is harmful, we now bring the discussion closer to political realities by pragmatically supposing it is: a society with fewer addicts is assumed preferable to one with more. Abstinence is worth pursuing.

Reasons for seeking harm-minimisation by limiting health costs and the costs of crime contingent on heroin use are simple for even libertarians to uncover. It is impossible (or difficult) to recover these types of costs by levying efficient prices for health care or by fully recouping crime costs through fullliability criminal sanctions. Health care is commonly regarded as a 'merit good' that should be priced at less than its cost, while drug user budget constraints, and uncertainties in criminal detection and prosecution, limit the potential for fullliability damage recovery from criminals.

Note that pursuing abstinence and harm-minimisation targets typically involves two independent objectives. Trying to minimise harm through public provision of heroin can advance harm-minimisation objectives but, by reducing the costs of addiction, can reduce abstinence levels. Similarly, pursuing strong abstinence objectives by imposing stringent legal sanctions can perhaps increase the harm caused by heroin by raising heroin supply prices and causing additional overdose deaths. It is only if abstinence objectives are entirely achievable that harm-minimisation is also automatically ensured. Otherwise, there is a trade-off between these aspects. 


\section{Background: The Swiss Trials}

Sections of the Australian medical profession and some social workers dealing with addiction have argued strongly for public provision (Bammer, 1995; Wodak, 1997). These arguments often cite evidence from a Swiss heroin trial claiming impressive health outcomes. In this trial 1,146 addicts were supplied with heroin over 18 months. There were no overdose deaths, only three new HIV infections, four of hepatitis B and five of hepatitis C. Reported income from crime dropped from 69 per cent to 10 per cent of total income, criminal offences fell by 60 per cent and permanent employment increased from 14 to 32 per cent. Finally, net savings of $\mathrm{A} \$ 45$ per day occurred after accounting for treatment costs, due to resulting reduced criminal investigation and imprisonment costs (Uchtenhagen, 1997).

The Swiss trials however are now coming under criticism so arguments supporting public provision that are based purely on them seem premature. Psychosocial care was given to addicts as well as legal heroin with these trials, so heroin provision alone cannot be credited with claimed health and other benefits. The experimental design of the trials would need to have been modified to admit a control group receiving welfare benefits but not legally supplied heroin to justify claims over what determined outcomes. The claims concerning reduced criminality and health are partly based on anecdotal evidence. They are inconclusive given preselection difficulties and the experimental design problem mentioned. Most important, the Swiss study's outputs have not, as yet, been published in professional journals and then subjected to the standard types of scientific scrutiny (Aeschbach, 1999; Farrell and Hall, 1998).

The Swiss study provides procedural insights into conducting trials but does not provide compelling evidence for public provision. It does not consider competing arguments for treatment using methadone as an alternative to heroin (Metrebian et al., 1998 compare treatments), needle exchanges, or for treatment aimed at achieving abstinence rather than steady state addiction. Nor does the study consider competing arguments for complete legalisation which is an option if treatment costs are prohibitively high only because public provision is restricted to addicts alone. While further trials, in Australia and elsewhere, can account for design criticisms of the Swiss approach, it is important that such trials be carried out in an atmosphere where sensationalism and misinformation do not drive a flawed radical agenda.

Conducting an experiment itself can be socially costly if experimenters have interest group motivations in supporting certain forms of treatment. A number of critics have argued that managers of the Swiss project have attempted to drive Swiss policy using their research findings. Important addiction management (and scientific design) issues tend to be overlooked when researchers use 
experiments to attempt to drive policy (Aeschbach, 1999; Farrell and Hall, 1998).

We should finally mention that there are other instances where narcotics have been prescribed to addicts. In the United States, from 1919 to 1923, over 40 clinics prescribed morphine. Heroin prescription commenced in the United Kingdom in 1926 and continues today but only on a very limited basis (RihsMiddel, 1997).

\section{Addiction Costs}

Long-standing evidence on addictive drugs shows that demand is surprisingly price-sensitive. Saffer and Chaloupa (1995) use United States data to estimate a price elasticity of heroin demand between -1.8 and -1.9 . Participation elasticities lie between -0.8 and -0.9 . The recent explosion in heroin use in Australia has been associated with much lower prices and is consistent with the hypothesis of high elasticity. Applying the Saffer and Chaloupa estimates to Australian heroin price falls since 1990 (from $\$ 50$ to $\$ 25$ per cap) rationalises an expansion in heroin consumption of 92 per cent and in new user numbers of 42 per cent over this period.

Partly, the growth that has occurred in Australia has come from increased numbers of new users (particularly females) seeking to experiment. Incentives to experiment are stronger if prices are low, particularly if, as evidence suggests, cheap heroin can substitute for other more widely-used drugs such as marijuana (Maher et al., 1998). Some of these additional new users will become addicts thereby increasing long-run heroin demands. It is also worth observing that addicts (and non-addicted long-term casual users) will increase the quantity and frequency of their heroin use with lower prices.

If public provision of heroin is associated with lower prices for heroin, this will augment long-run total heroin demands. Moreover, lower prices do seem likely both in legal markets servicing addicts and in illegal markets servicing new (and so-called 'recreational') users of heroin. Public provision reduces the market price of illegal heroin because addicts will switch from illegal markets to cheaper publicly-provided heroin. Addicts then face weaker incentives to reduce use. In addition, new users face lower costs of experimentation because illegal supplies are now cheaper, and public provision at low prices is guaranteed should they become addicted. If there are social disapproval costs of using heroin which limits its demand, these are diminished if governments guarantee to provide supplies to addicts. Addiction then becomes a 'state-managed health problem'. 


\section{Effects of Public Provision on the Illegal Heroin Market}

Providing legal heroin has effects on the operations of illegal heroin markets. If supply is less than perfectly elastic then reduced demands by addicts for illegal heroin will influence prices charged in the illegal market. There are at least two possible approaches to modelling such effects.

\section{Standard analysis of the effects of reduced illegal demands}

The substantial profits in the heroin trade suggest that heroin prices are well above heroin's marginal cost to wholesalers. In part, however, these profits indicate a 'normal return' for suppliers operating in a high-risk environment. Hefty jail sentences, fines, and property confiscations are imposed on those caught trafficking and supplying heroin. Financial rip-offs, assaults and murders also accompany some heroin deals increasing transaction costs.

At the street level, however, we argue below that heroin supply is fairly competitive. Then, given a reduced demand for illegal heroin, we should expect a reduced quantity supplied via an exit of firms from the industry. This is described in the diagram below.

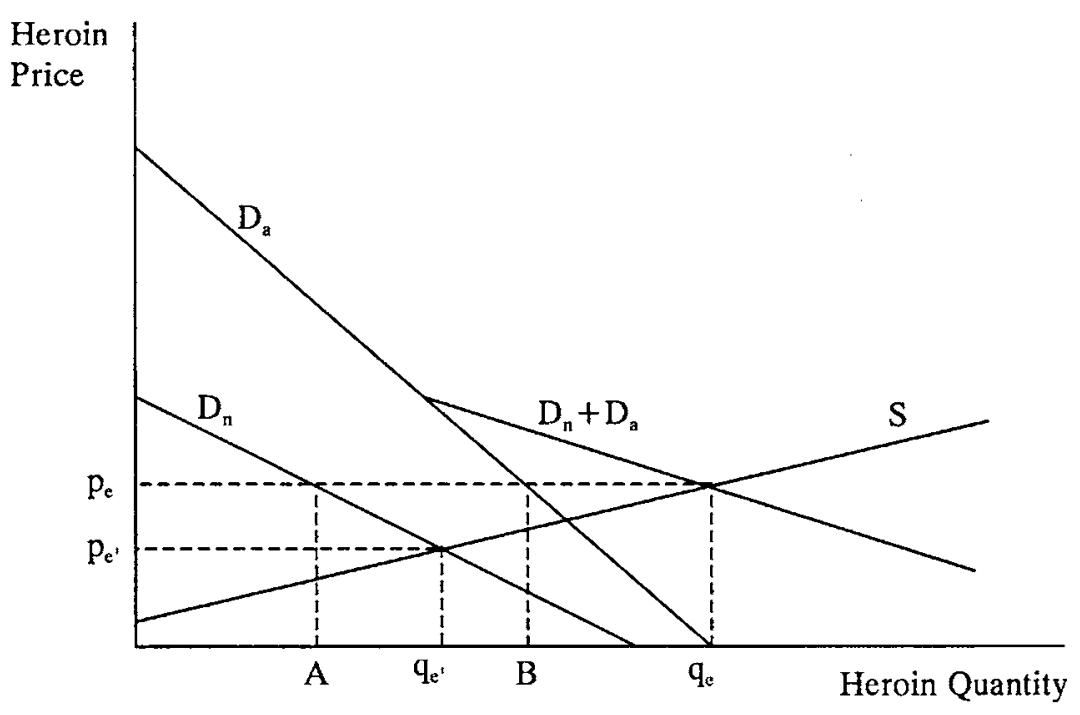

Here addicts have a demand for heroin $D_{\mathrm{a}}$. New users have the more elastic demand $D_{n}$ so, in the absence of legal supplies for addicts, the aggregate demand for illegal heroin is $D_{n}+D_{a}$. The illegal supply curve for heroin at street level is S. Then, with market-clearing, the price of illegal heroin without publicly 
available supplies is $p_{e}$ and the equilibrium quantity delivered to users is $q_{e}$. Note that, unlike Bardsley (1997), we do not allow for price discrimination between the two classes of user. The complications raised by admitting discrimination are discussed below.

With public provision to addicts, illegal suppliers only provide heroin to new users at price $\mathrm{p}_{\mathrm{e}}{ }^{\prime}<\mathrm{p}_{\mathrm{e}}$. At the lower price the demand by new users increases from $A$ to $\mathrm{q}_{\mathrm{e}}{ }^{2}$. In addition, to encourage addicts away from illegal suppliers, public providers must set a price for legal heroin below that charged in the illegal market so demands by addicts also increase. In short, creating a legal market for supplying heroin to addicts increases demands for heroin both by new users and addicts. Dependence by addicts on the illegal market is eliminated and the size of the illegal heroin market reduced. This reduction, however, is more than offset, in terms of total heroin consumption, by an expansion in the legal market for addicts and in the illegal market by new users

Strictly speaking there are two qualifications to this analysis. First, price is only lower with public provision if legal supplies are accessed from a different source than illegal supplies and hence do not only displace illegal demands. This is plausible given the separate market for opiates used in medicine. Second, we ignore connections between demand by addicts and illegal supplies. Many addicts fund their addiction by selling heroin. If addicts receive publiclyprovided heroin they may cease supplying illegal heroin providing an offsetting shift to the left in the heroin supply curve and somewhat higher prices than would otherwise prevail.

Although addict numbers increase with legal provision, these addicts may be more benign to themselves and to society than were previous illegal addicts. Describe them as benign addicts. Benign addicts may be less likely to overdose or to commit crime if provided with low-priced heroin under supervised conditions. If an abstinence objective is then pursued, the expansion in heroin use and addiction that would follow legal provision to addicts would be seen as socially costly. However, that legal supplies increase and illegal supplies decrease with public provision provides possible offsetting gains by advancing harm-minimisation objectives.

The increased illegal heroin sales to new users are a less positive outcome of public provision. Some of these new users will become addicted and will therefore come to depend on the public provision program. Some will overdose while still new users. This can be significant if inexperience on the part of new users and the related inability to judge drug quality are an important cause of overdosing. If this is so then both the incidence of addiction and overdosing among new users will increase when cheaper illegal heroin supplies follow its public provision to addicts.

The increase in the quantity of heroin demanded by new users depends on heroin's supply elasticity. If supplies are perfectly elastic, because Australian heroin retailers are price-takers in international markets, new user demands do 
not expand because prices remain fixed. This is, however, implausible. Even if retailing of heroin is competitive, the wholesale prices charged to distributors are likely to be demand-sensitive so retailer supply curves for heroin will be upward-sloping.

The above analysis utilises a simple model of addictive behaviour where new users respond only to current heroin prices. The Becker-Murphy (1988) 'rational addiction model' suggests that drug users display forward-looking behaviour and inter-temporally optimise. This suggests new user demands depend on future as well as current prices. Public provision of heroin to addicts at low prices shifts the demand curve by new users outward in response to anticipated lower future prices. This further expands the business transacted between illegal suppliers and new users. Thus, accounting for forward-looking behaviour intensifies the negative effects on abstinence objectives of public provision. More new users will be seen to consume drugs when forwardlooking behaviour occurs and there will be a higher long-term incidence of addiction. (Note, even if heroin supplies were perfectly elastic - so illegal prices did not fall with legal provision - the dependence of new user demands on future prices still promotes increased demands as a consequence of public provision.)

\section{Price discrimination}

Bardsley (1997) and Gans (1997) consider possible price discrimination by monopolistic heroin suppliers. This has potentially different implications for assessing the public provision of heroin. The idea is that illegal suppliers might initially provide new users with heroin at low prices to induce addiction. Having achieved this, suppliers then pitch sales to the resulting addicts at higher prices reflecting their less elastic demands. With government-supplied sales to addicts this mechanism will not operate. Dealers will be unable to achieve eventual high returns because addicts never purchase from them. Gans suggests this effect will limif supply to an extent offsetting the demand-creating effects discussed.

Even if this argument is correct it is based on strong market structure assumptions. Currently, the retailing of illegal heroin seems close to being a competitive market. ${ }^{1}$ There are many suppliers and little need for buyer loyalty. Buyers can shop around and purchase at the best price. New users could also arbitrage price differentials and re-sell cheap heroin to long-term addicts. There are thus limited possibilities for addicting a new user and then monopolistically

\footnotetext{
${ }^{1}$ Evidence on United States heroin markets supports this claim. While the structure of overall supply is hierarchical, the retail end of the market is competitive. Users have good information about price and quality and experiment with the products of different suppliers (Lee, 1993:945-6). Evidence for Australia is patchy, but Maher et al. (1998) suggest that new users often pay a higher price than addicts because greater risks are associated with selling to new or unknown users.
} 
supplying them subsequently as addicts at higher prices. It seems more plausible to believe that, as a consequence of competition, new users and addicts are usually supplied heroin at comparable prices which suggests the standard analysis adequately describes illegal market responses to public provision.

\section{Pricing Legal Supplies}

The extent to which heroin prices are set below illegal prices in the public market is an important policy issue that is little discussed in the debate over public heroin provision. An implicit assumption is that, as in the Swiss trial, heroin will be freely supplied to addicts up to some fixed maximum amount per day. Without the latter quantitative constraint on supply, the lower the price, the greater will be an addict's heroin demands. With quantitative constraints on supply, addicts may be tempted to utilise illegal markets to boost use. Clearly, prices need to be set below illegal supply prices for illegal supplies to be curtailed.

How low should legally-supplied heroin prices be? Should a zero price be set? If prices are set low then addicts need to rely very little on crime to finance their addiction. However, low prices have a strong stimulating effect on demands by new users since this reduces their expected future costs should they become addicted. These increased demands also encourage increased overdose problems among new users and a higher incidence of addiction. Choice of price for legally-supplied heroin involves trading-off advantages from reduced criminal costs against the expansion of the new users' market and the increased possibilities for overdoses.

If policy makers place low weight on abstinence objectives and high weight on the harm-minimisation that occurs by reducing dependence on illegal markets, they will price heroin low in legal markets. The assumption is that, although more addicts are created via public provision, they will not increase social costs due to the low public heroin price and the controls imposed via public provision. Conversely, should policy makers strongly favour abstinence objectives, they will charge a much higher price for legally-supplied heroin.

In the United States, the Controlled Substances Act provides 'zero tolerance' guidelines for illicit drug penalties. Those convicted of unlawful distribution, possession with intent to distribute or manufacture of illicit drugs face decadeslong imprisonment and fines of up to $\$ 10 \mathrm{~m}$ even for their first offence. A firsttime offender possessing more than five grams of a drug can serve from five to twenty years in prison and be fined $\$ 250,000$. Apart from lacking 'fairness', a consequence of such penalties is the well-known incentive created to pursue major crime. The effect of United States zero tolerance policies has been to create a high incidence of long-term imprisonment in the general population. At various times, however, zero tolerance policies have been advocated in Australia. 
Should policy makers seek abstinence alone and ignore harm-minimisation, the case for zero tolerance criminal prosecution of heroin use and the crimes involved in supporting heroin use strengthens. Conversely, if policy makers only seek harm-minimisation and ignore abstinence objectives, then the case for public provision of heroin to all by complete decriminalisation dominates arguments for provision to addicts alone. That neither zero tolerance nor public provision-to-all has widespread support reflects the increasingly high costs of abandoning one of these targets and then single-mindedly pursuing the other.

Some skepticism has emerged with respect to traditional arguments on the causes of so-called 'overdose' deaths due to heroin use. Recent research suggests overdoses occur because heroin is used in conjunction with other drugs (such as benzodiazepines which are types of tranquilisers) and/or alcohol rather than because users are inexperienced and face problems of judging heroin purity (Zador et al., 1996; Hall, 1996). ${ }^{2}$ Many overdose deaths seem to occur among long-term heroin users who, while being experienced in judging product quality and dosage, tend to be dependent on these other drugs. This is problematic, because as the Swiss trials demonstrate, public provision of heroin has had only limited effects in reducing demands for these other drugs. Should this new view of the reasons for overdosing be correct, overdoses may continue to occur, even with legal provision, among both addicts and new users. ${ }^{3}$

Therefore setting a very low price for heroin that is legally-supplied has dubious benefits. It will expand the number of new users, increase heroin consumption by existing users and, in the longer term, increase the number of addicts. These trends can worsen overdose problems even if a public program monitors dosage levels and reduces infection risks. If public provision is initiated, the price charged for heroin should be high enough to discourage excessive new use of the drug.

\section{Risks of Addiction}

Recent research on policies for dealing with addiction (Clarke, 1998) focuses explicitly on the risks addiction creates for heroin users rather than on price effects. Some of these risks relate to the extent of drug use and are referred to as addiction-dependent risks. These risks increase with drug use in both the short and longer term. Examples include medical damage (for example, to liver or brain), risks of becoming more accident-prone and, it is argued, risks of

\footnotetext{
${ }^{2}$ Zador et al. (1996) analysed 152 heroin-related deaths in NSW in 1992 and found 82 per cent of those who died were older males (mean age 29.7 years). Alcohol was detected in 45 per cent of deaths (with mean blood alcohol of $0.14 \mathrm{~g} / 100 \mathrm{mls}$.) while benzodiazepines were detected in 26 per cent of deaths.

${ }^{3}$ To be clear, there were no overdose deaths in the Swiss trials. However, as Uchtenhagen (1997) points out, dependence on tranquilisers did not fall during these trials. If newer theories of overdosing are correct, then synergies between tranquilisers and heroin could continue to induce overdoses even with public heroin provision.
} 
overdose and legal risks of fines and imprisonment that are use-related. In the criminal justice system the degree of addiction dependence is often assessed by considering numbers of prior convictions. This then helps determine sentencing.

Other risks are less related to use, but conditional on other factors indirectly associated with use such as the risks of HIV or hepatitis infection from shared syringes. Other use-independent risks include legal risks that are unrelated to the extent of use such as laws that criminalise the use of heroin entirely. These are addiction-independent risks since they arise regardless of the scale of drug use.

Use of addictive substances will fall if addiction-dependent risks bear on addictive substance purchases. Users attempt to avoid the adverse possible consequences of use. However, if hostile, use-independent risks increase, use can be stimulated. If a user's environment is hostile regardless of use, there is little incentive to restrict use. If users face a difficult future regardless of their use decisions then they face low incentives to limit current use pleasures. Thus one way of reducing use is to increase use-dependent risks and reduce useindependent risks:

- Increasing use-dependent risks rationalises punishing addicts via usedependent sanctions and by making users aware of the health and other risks contingent on use. Penalties and costs of use should be use-dependent.

- Reducing use-independent risks means improving the life environment of users so they have motivation to reduce their drug dependencies. This suggests setting up needle exchanges to reduce infection risks, offering opportunities for detoxification and improving social and work skills.

The ultimate penalty for heroin use is the non-officially sanctioned death of the user. If overdoses and other such causes of death are perceived by users to be use-dependent, then policies for reducing their impact increase addiction in the community by eliminating costly consequences of addiction. Reducing usedependent mortality risks encourages addictive drug use and therefore addiction.

This does not mean overdose deaths can be justified (and used) to prevent addiction. It does however imply that moves to reduce mortality risks associated with heroin use will stimulate use. This is fact not a moral judgement. If society seeks to inhibit use and addiction levels, as well as overdose deaths, it must account for this link. If public heroin provision reduces addictiondependent risks then it encourages increased use. If users feel that becoming addicted poses less health problems because of reduced overdose risks, they will be less motivated to avoid addiction. 


\section{Empirical Issues}

Consumption of heroin in Australia is currently illegal. Data on user numbers, consumption and the social costs of associated crime are therefore inherently uncertain. Given this uncertainty, there is a need for caution in using published data to help formulate policy. Data on alternative proposed treatment costs and success rates can reflect institutional self-interests in making claims on the public purse. Politicisation of illicit drug use statistics then compounds inherent inaccuracies due to illegality. A frequent, irreverent remark in the illicit drug management literature is that 'a nation has as many addicts as it chooses to discover'. One approach to resolving this arbitrariness and lack of data is to consider a range of data and then to simulate possibilities. This is the approach adopted here.

The tenor of our previous arguments was that proposals for public heroin supplies at low price raise the prospect of adverse outcomes. We now provide data supporting this view. Consider a two period world, 'now' (when addict and new user numbers are given) and the 'future' (when public provision to addicts is an option, when the number of new users varies with the heroin control regime and when some new users become addicts). The policy objective is minimisation of future total heroin use costs.

Data on current heroin use are extrapolated from Drug Advisory Council (1996). This suggested 59,000 regular ('addict') heroin users and 113,000 irregular (or 'new') users in Australia in 1990. During the 1990s heroin prices fell from around $\$ 50$ per cap in 1990 to $\$ 25$ in 1999 . It seems reasonable to suppose that, in 1999 , there are 50,000 to 100,000 regular users ('addicts') and 150,000 to 450,000 irregular ('new') users. We allow for a low number of addicts to reflect possible 'alarmism' by those involved in treating addicts. Marks (1992) suggests reasons for a high possible level of new users.

Trends in new user numbers and levels of future addiction depend on future heroin prices. Consider two scenarios:

1. Without public provision suppose heroin prices remain at 1999 levels of $\$ 25$ per cap. Then if most current addicts remain alive (and addicted) it is only current new users who will add to addict numbers. Suppose one third of current new users become addicted. This recruitment into addiction figure is widely used (Gittins, 1999). One might conjecture that the fraction becoming addicted would depend on price so if prices are low, new users use more and more readily become addicted. Ignoring such complications, and accepting the one-third figure, future addict numbers will lie between 100,000 to 250,000 . 
2. With public provision suppose heroin prices fall to $\$ 12.50$ per cap. This price fall leaves heroin prices well above heroin's marginal cost to wholesalers and does not seem implausible. For example, if addict demands initially comprised 70 per cent of consumption then a price fall of 50 per cent following the disappearance of such demands implies an elasticity of supply of 1.4 which seems reasonable. The actual fall depends largely on current addict consumption but, given lack of data, this dependence is ignored. A price fall of 50 per cent will strongly stimulate heroin use among non-addicts. If the Saffer and Chaloupa (1995) estimates for participation elasticities in United States markets apply to Australia, the hypothesised price fall will expand new user numbers by 45 per cent to a range of 217,500 to 652,000 . The upper limit here is double the figure that Marks (1992:538) cites for 1987. Given the substantial growth in use during the 1990s the figure seems possible. Suppose one-third of additional new users become addicted. Then, numbers addicted increase by a further 22,500 to 67,500 over the case above.

Treatment costs under public provision are significant because addicts need both to be supplied with heroin and prevented from reselling it. Treatment will apply both to current addicts and to the new addicts created by public provision. Reflecting lower labour costs, and possible scale economies, suppose net daily public provision costs per addict in Australia are 70 per cent of costs in the Swiss trial (which were $\$ 51$ per day). This amounts to $\$ 35.70$ per day or $\$ 13,030$ annually per addict.

Funding such costs seems unrealistic in an Australian public health policy setting. Total Commonwealth Government funding of the Medicare Agreement in Australia over the five years 1998 to 2003 will average $\$ 6$ billion. Hence, depending on actual future addict numbers as estimated above, public provision to addicts would cost between 26 and 70 per cent of total planned Commonwealth outlays under Medicare. While it might be objected that it has never been proposed to supply all Australia's addicts with heroin, the per addict costs of treating smaller groups are likely to be larger than a more inclusive program. With a small group, per addict treatment costs are large.

The major benefit from public provision is a claimed reduction in crime and overdose costs. Making an assumption favourable to the case for public provision, suppose all property crime costs (transfer plus enforcement costs) and overdose deaths are eliminated by this policy. Property crime costs in the form of forced transfers (theft) due to heroin use are estimated at $\$ 10,920$ per addict (Maher et al., 1998). From 1988 to 1992 illicit drug enforcement costs grew by 40.5 per cent to reach $\$ 450 \mathrm{~m}$ (Collins and Lapsley, 1996). Assuming a similar proportionate increase from 1992 to 1999 , and supposing that all such costs are related to heroin use, heroin-linked crime enforcement costs would rise to $\$ 783 \mathrm{~m}$ in 1999 . Assume this represents the net future likely cost of heroin- 
related crime without public provision. Finally, suppose the financial benefit (in terms of output gained, reduced grief) from saving an addict's life is $\$ 200,000$ per addict and that 600 deaths per annum (the aggregate fatal overdose figure for 1997) would be saved by public provision in the future. Then there are further future savings from public provision of $\$ 120 \mathrm{~m}$ annually.

It is now possible to compare costs of continuing to pursue current policies rather than moving to public provision for addicts. With current policies we estimate future addict numbers to range between 100,000 and 250,000 and for associated crime, crime detection and overdose costs to lie between $\$ 2$ billion and $\$ 3.6$ billion. With a change to public provision, future addict numbers lie in the higher range, 122,500 to 317,500 . Although, on our assumptions, all crime and overdose costs are eliminated with public provision, health costs of treating this larger addicted population lie between $\$ 1.6$ billion and $\$ 4.2$ billion.

What is interesting here is that aggregate costs are only lower with public provision in situations where the heroin problem is at the optimistic end of its possible scale. It is only if there were initially few addicts and few new users that public provision provides net savings. Then there are net savings attributable to public provision of up to $\$ 400 \mathrm{~m}$. Otherwise, extra treatment costs swamp benefits from reduced crime and reduced overdose deaths. At the pessimistic end of the heroin use scale, net additional costs of legal provision rise to over $\$ 500 \mathrm{~m}$. Moreover, this assumes no weight on abstinence objectives. If costs are attached to creating new addicts then the public provision case is even less favourable. ${ }^{4}$

There are two possible consequences of this view. One is to avoid public provision by retaining current heroin penalties. Another possible implication is a case for complete liberalisation of heroin markets which would reduce the high costs of public provision by eliminating the need to prevent resale to nonaddicts. This leads to substantial benefits from reduced crime without low treatment costs but implies a greater increase in the pool of addicts. Indeed, the possibility of high costs has led some observers to see arguments for public provision to addicts as a 'stalking horse' for decriminalisation (Oakes, 1999).

The data used in these simulations can be questioned. Better evidence is sought on addict and new user numbers as well as rates of recruitment of new users into addiction. The point of the current exercise however is not to provide precise forecasts of the consequences of public provision but to show that, with plausible data, public provision may have very negative consequences. It may imply a case for either retaining the current system or for moving towards a fully-liberalised system.

\footnotetext{
${ }^{4}$ Attaching an annual cost of $\$ 10,000$ to creating a new addict, increases the cost of public provision from $\$ 225 \mathrm{~m}$ to $\$ 1,673 \mathrm{~m}$. The cost of public provision rises 50 per cent. With such abstinence costs included, net benefits of provision at the optimistic end of the scale fall to $\$ 175 \mathrm{~m}$ while at the pessimistic end of the scale net costs of public provision rise to $\$ 2.3$ billion.
} 


\section{Conclusion}

If Australia seeks to minimise the harm associated with heroin use by publicly providing heroin to addicts it must decide, first, how many additional long-term drug-addicts it will accept to achieve this reduced harm and, second, how much it is prepared to pay for public provision. The trade-off between pursuit of abstinence and harm-minimisation objectives needs examination as well. It is important to check that benign addicts do not continue to experience overdose problems related to synergies between different drug uses rather than drug quality uncertainty since this would largely thwart the motivation for public provision.

Transferring addicts from dependence on illegal suppliers to legal suppliers can only occur if incentives, such as lower prices and lower use-dependent risks, apply to legal supplies. Such a switch in demand reduces the profits of drug suppliers and forces them to charge lower prices to new users. Thus public provision will increase demand for heroin by addicts, encourage additional demands by new users from illegal suppliers and, in the long-term, increase the supply of addicts. This is the major argument against public provision of heroin.

Of particular concern are the high price and participation elasticities of demand that some have identified for heroin consumption. These suggest that substantially higher levels of long-term addiction, as a by-product of much increased new user demand, may stem from the public provision of heroin at low prices to current addicts. The public provision of heroin is expensive. Ignoring abstinence objectives, complete liberalisation can dominate arguments for public provision to addicts alone.

The main virtues of public provision are that crime costs associated with financing addiction are reduced and that there is an increased ability to monitor doses and the conditions under which drugs are administered thereby reducing overdoses due to uncertainty and inexperience. Setting a low price on public supplies of heroin advances the prospects of reducing criminal damages, occurring as a by-product of heroin use. However, this will be at the expense of abstinence objectives - low prices will expand demands by new users and hence increase longer-term addiction.

The argument above discusses the case for public provision rather than a provision trial. A trial would yield additional information to decision makers but perhaps not much. The most valuable information relates to treatment costs although, given economies of scale in public provision, a trial would at best provide upper-bound estimates on costs. In terms of addict behaviour the implications of providing heroin at low cost seem in some cases almost a priori obvious. If a trial is conducted then it should remain an experiment. It should not become an attempt by experimenters to push politically an approach to treatment favoured for reasons of institutional self-interest. Crucial concerns in any assessment of such an experiment depend on decision makers gaining an 
improved understanding of the reasons for overdose deaths, information on addict and new-user population sizes and information on the social costs caused as a by-product of illegal heroin use. Trials will perhaps yield less information about these issues than more direct surveys of current addict behaviour.

\section{References}

Aeschbach, E. (1999), 'On the Scientific Value of the Research Studies Accompanying Heroin Distribution: A Critique’, mimeo, Zurich.

Australian Institute of Health and Welfare (1996), Australia's Health 1996, AGPS, Canberra.

Bammer, G. (1995), Report and Recommendations of Stage 2 Feasibility Research into the Controlled Availability of Opioids, Australian National University, Canberra.

Bardsley, P. (1997), 'Dynamic Addiction Games', mimeo, Department of Economics, University of Melbourne.

Becker, G. and K. Murphy (1988), 'A Theory of Rational Addiction', Journal of Political Economy 96: 675-700.

Clarke, H. (1998), 'Addictive Consumption Under Conditions of Risk', mimeo, Department of Economics and Finance, La Trobe University.

Collins, D. and P. Lapsley (1996), The Social Costs of Drug Abuse in Australia in 1988 and 1992, AGPS, Canberra.

Drug Advisory Council (1996), Drugs in Our Community, Melbourne.

Farrell, M. and W. Hall (1998), 'The Swiss Heroin Trials: Testing Alternative Approaches', British Medical Journal 316:639.

Gans, J. (1997), 'Illegal Drugs: the Supply Side', Australian Financial Review, April 22, p. 6.

Gittins, R. (1999), 'How Prohibition Helps Cap Heroin Use', The Age, March 3, p 14.

Hall, W. (1996), 'How Can We Reduce Heroin 'Overdose' Deaths?', Medical Journal of Australia 164:197.

Lee, L. (1993), 'Would Harassing Drug Users Work?', Journal of Political Economy 101(5):93959.

Maher, L., D. Dixon, M. Lynskey and W. Hall (1998), Running the Risks: Heroin, Health and Harm in South West Sydney, National Drug and Alcohol Research Centre, University of New South Wales (NDARC Monograph No. 38).

Marks, R. (1992), 'The Costs of Australian Drug Policy', Journal of Drug Issues 22:535-47.

Metrebian, N., W. Shanahan, B. Wells and G. Stimson (1998), 'Feasibility of Prescribing Injectable Heroin and Methadone to Opiate-Dependent Drug Users: Associated Health Gains and Harm Reductions', Medical Journal of Australia 168:596-600. 
National Drug and Alcohol Research Centre (1999), Overdose Fact Sheet, University of New South Wales.

Oakes, L. (1999), 'Why Jeff Kennett is Pushing the Drugs Debate', The Bulletin, March 9, p. 28.

Rihs-Middel, M. (ed.) (1997), The Medical Prescription of Narcotics. Scientific Foundations and Practical Experience, Hogrefe and Huber, Seattle.

Saffer, H. and F. Chaloupa (1995), 'The Demand for Illicit Drugs', National Bureau of Economic Research, August (NBER Working Paper No. 5238).

Uchtenhagen, A. (1997), 'Summary of the Synthesis Report', in A. Uchtenhagen, F. Gutzwiller and A. Dobler-Mikola, (eds) Programme for the Medical Prescription of Narcotics: Final Report of the Research Representatives, Zurich: Institute for Social and Preventative Medicine at the University of Zurich.

Wodak, A. (1997), 'Public Health and Politics: The Demise of the ACT Heroin Trial', Medical Journal of Australia 167:348-53.

Zador, D., S. Sunjic and S. Darke (1996), 'Toxicological Findings and Circumstances of Heroin Caused Deaths in New South Wales, 1992', National Drug and Alcohol Research Centre, University of New South Wales (Monograph No. 22).

The author thanks members of La Trobe University's Thursday Economics Discussion Group for comments. Peter Lloyd, Yew-Kwang Ng, Lou Will, the Editor and an anonymous referee also made valuable remarks. Finally, Lee Smith provided her usual excellent editorial and research assistance. The author bears responsibility for views expressed. 